\title{
¡ALTO AHÍ A LA «IDENTIDAD CONSTITUCIONAL»! UN EJEMPLO (YA NO TAN) RECIENTE DE DISCONTINUIDAD CONTINUISTA EN LA JURISPRUDENCIA IUSCOMUNITARIA DEL TCFA*
}

\author{
ANTONIO LÓPEZ CASTILLO \\ Catedrático (A) de Derecho Constitucional \\ Universidad Autónoma de Madrid
}

SUMARIO

I. La decisión: contexto y concepto. II. La decisión en (complementaria) perspectiva ius europea... III. ...y constitucional nacional IV. Consideraciones finales, a modo de conclusión.

\section{LA DECISIÓN: CONTEXTO Y CONCEPTO}

La Sentencia de la Sala Segunda del Tribunal Constitucional Federal Alemán (TCFA), de 15 de diciembre de 2015, de que aquí se trata, conoce de un recurso de queja por inconstitucionalidad en relación con una decisión jurisdiccional estimatoria de la solicitud (italiana) de entrega de un extranjero (estadounidense) detenido en Alemania, en aplicación del Derecho de la Unión Europea (DUE) ${ }^{1}$.

La Sentencia se enmarca en un denso contexto, caracterizado por la alta tensión constitucional que genera el régimen de aplicación de la llamada euro orden, según se pone de manifiesto en este recurso de queja por inconstitucionalidad, y

* El presente trabajo se inserta en el marco del proyecto de investigación DER2016-78391-P, sobre «El control de la ley = constitucional, comunitario y convencional», financiado por MEIC.

1 Entre los comentaristas que he podido consultar pueden mencionarse aquí, por otros, en lengua alemana, M. NetTesheim (Anmerkung zu BVerfG. Beschluss vom 15. Dezember 2015, en Juristen Zeitung 2016, 424-8), C.D. Classen (Zu wenig, zu fundamentalistisch — zur grundrechtlichen Kontrolle «unionsrechtlich determinierter» nationaler Hoheitsakte, en EuropaRecht, 2016/3, 304-12) y D. BuRCHARDT (Die Ausübung der Identitätskontrolle durch das Bundesverfassungsgericht, en ZäoRV 76, 2016, 527-51). Y, en lengua española, X. Arzoz Santisteban (Karlsruhe rechaza la doctrina del Tribunal de Justicia y advierte con el control de la identidad constitucional, en REDE 58, 2016). 
contribuye a alimentar ese corpus conceptualista que, mediante una especie de inversión metodológica ${ }^{2}$, con tanto denuedo y afán viene elaborando el TCFA (en la perspectiva de lo específico y propio sobre el fondo de lo «común» y «comunitario» $\left.{ }^{3}\right)$.

Por lo que al tema de fondo se refiere, la sentencia del TCFA de 15 de diciembre de 2015, dictada en el asunto $2 B v R 2735 / 14^{4}$, es una manifiesta expresión de inquietud ante una jurisprudencia del TJUE que se considera insatisfactoria.

El TCFA, a la vista de un frustrado episodio de institucionalizado diálogo previo a iniciativa del TC español (en el asunto Melloni de referencia, que parece haberse tenido bien presente como supuesto de elusivo ejercicio de su responsabilidad jurisdiccional por parte del TJUE), antes que insistir ante el TJUE, mediante planteamiento de una segunda cuestión prejudicial (pendiente aun entonces de respuesta prejudicial una primera $-\mathrm{y}$, hasta el momento, únicamodalidad de oferta formal y directa de condicionada interpretación de disposiciones y actuaciones sustentadas en una lectura del DUE que, por expansiva, se consideraba, si no a descubierto de títulos de actuación, potencialmente invasiva de «contenidos esenciales» de la LF $^{5}$ ), el TCFA se da a la tarea de interpretar el DUE de conformidad con contenidos que, como elementos integrantes de la «identidad constitucional» de la LF, condicionarían y limitarían la aplicación de toda disposición y actuación en el espacio constitucional alemán.

Al efecto, superando conocidos precedentes de interpretación (previa/temprana) de determinadas disposiciones del derecho primario de la UE de conformidad con elementos o aspectos nucleares de la LF (de «núcleo identitario» se hablaba ya en la sentencia Maastricht), el TCFA hace extensiva aquí esa técnica de interpretación de conformidad con la «identidad constitucional» (formulada como potencial cláusula paramétrica, desde la Sentencia Lisboa) a la determinación del sentido y alcance de la primacía de aplicación del Derecho derivado de la UE.

2 De un modo que ciertamente recuerda la noción de «pirámide conceptual» de la jurisprudencia de conceptos — dicho sea a la larenziana — (cf., por otros, M. Heidemann, Winscheid und «Begriffsjurisprudenz», Grin Verlag, 2015).

3 Por decirlo a la manera de los ius privatistas europeos (cf., por otros, N. JANSEN, Dogmatik, Erkenntnis und Theorie im europäischem Privatrecht, en Zeitschrift für Europäisches Privatrecht, ZEuP, 2005, pp. 750783), sin olvidarse por ello de que en el discurso ius publicista acerca de la presupuesta estandarización por «equivalencia» late una concepción semejante.

4 De esa misma fecha es la sentencia dictada, a propósito de la declaración de inaplicación de tratado bilateral con Turquía, mediante activación manifiesta de dualismo, en el asunto 2BvL 1/12.

5 A propósito del detalle de la condicionada «oferta» elevada mediante Auto del TCFA, de 14 de enero de 2014, y de la contenida respuesta del TJUE, mediante Sentencia de 16 de junio de 2015, asumida a regañadientes (no sin objeciones) por el TCFA, mediante sentencia de 21 de junio de 2016, me permito recordar que, a la hora de entregar este trabajo, siguen pendientes de resolución (presumiblemente no inmediata) por parte del TCFA, los asuntos 2 BvR 859/15, 2 BvR 1651/15, 2 BvR 2006/15, 2 BvR 43/16 y 2 BvR 980/16, recursos de queja por inconstitucionalidad, todos ellos, promovidos a propósito de las Decisiones del Consejo del BCE relativas a los programas PSPP, ABSPP, CBPP y EAPP, así como de las actuaciones al respecto tanto de la Dieta y del Consejo federales, como del Gobierno federal (para mayor detalle cf. Deutscher Bundestag, 18. Wablperiode, Drucksache 18/10652, de 14.12.2016). 
Y ello, porque — como, contra toda evidencia, se sostiene-, en su opinión («en su opinión», porque el rechazo de ese posible diálogo prejudicial no se basa sino en su apodíctica y asertiva negación de duda interpretativa alguna), la intervención del TJUE resultaría aquí innecesaria.

Ello es novedoso, sin duda. Y lo es, en la medida en que, como consecuencia de la inexcusabilidad paramétrica del estándar constitucional que, como elemento integrante de la «identidad constitucional», inequívocamente dice tener que aplicar, ni la tradicional divisoria entre ordenamientos, ni la deferencia ius europea en la asunción de su función jurisdiccional, se habrían de considerar ya un obstáculo para la efectiva y casuística declaración de inaplicación, sobre la eventual declaración de inconstitucionalidad del derecho nacional de remanente fuente nacional, tanto de derecho nacional ius comunitariamente predeterminado como del propio DUE.

De este modo, el TCFA anuncia algo que trasciende de la hipótesis de aplicación de estándares constitucionales propios en relación con supuestos relativos al enjuiciamiento del margen de apreciación de los poderes públicos alemanes, declarando, en su caso, la inconstitucionalidad del derecho nacional enjuiciado por vulneración de la correspondiente garantía iusfundamental ${ }^{6}$.

Pues, aunque en un sentido formal no se cuestione de plano la divisoria jurisdiccional conforme a la cual al TJUE le compete el enjuiciamiento del Derecho derivado y al TCFA el control del derecho nacional, de facto se avanza en la superación de una divisoria característica en su jurisprudencia ius europea. En la medida en que, sin insistir en la palmaria consideración del DUE como objeto inmediato de control (de aplicación), según el viraje doctrinal sentado en Maastricht (a propósito de su expresa exclusión previa de control de las actuaciones de un organismo supranacional, en la jurisprudencia Eurocontrol), se enfatiza la incondicionalidad de una cláusula de «identidad constitucional» que, como límite insuperable, se alzaría ya frente a toda manifestación de poder público constituido, y, por tanto, también frente al legislador de la integración, en presencia de un supuesto singular, sin necesidad de esperar ya a la concurrencia de hipótesis de falencia sistémica o deficiencia estructural del sistema de tutela (superando así, definitivamente, la suspensión de reserva de jurisdicción sentada en la secuencia Solange-II/Plátanos).

Pero, antes de insistir en su incidencia sobre el estado de la cuestión y avanzar alguna consideración proyectiva (IV), se impone aquí una aproximación, aunque sintética, más pausada, en una complementaria perspectiva ius europea (II) y constitucional nacional (III).

6 Cf., a propósito de esta misma problemática material, la controvertida declaración de inconstitucionalidad de la legislación de inserción de la euro orden en el ordenamiento nacional alemán, mediante Sentencia, de 18 de julio de 2005, as. BvR 2236/04 (cf. VV. PP.); cf., por otros, C. Tomuschat, Umgereimtes/Zum Urteil des Bundesverfassungsggericht vom 18. Juli 2005, en EuGRZ 2005, pp. 453-60. 


\section{LA DECISIÓN EN (COMPLEMENTARIA) PERSPECTIVA IUS EUROPEA...}

En síntesis, puede decirse que la queja por inconstitucionalidad concierne a un asunto recurrente en la Europa abierta al reconocimiento mutuo de sus resoluciones jurisdiccionales en el marco de su constitutivo espacio de libertad, seguridad y justicia ${ }^{7}$.

Y, más concretamente, puede decirse que en el conflicto planteado late la enjundiosa cuestión de ¿Cómo conciliar el avance en la efectiva práctica de un modelo simplificado de «extradición» al interno de la Unión Europea, a mitad de camino entre la comunitarización y el mutuo reconocimiento de los respectivos sistemas normativos, con la debida salvaguarda de estándares ius fundamentales que, directa o mediatamente, como presupuesto, condicionante y límite, sujetan el ejercicio de potestades públicas en el espacio constitucional que sustenta y enmarca el desenvolvimiento constitucional de los Estados miembros de la Unión Europea?

En lo que sigue, se presenta, a grandes rasgos, el desarrollo procesal de la queja por inconstitucionalidad planteada al TCFA (a), y, en relación con ello, se recuerda el trasfondo constitucional (español) del asunto Melloni (b) que, salvo errónea apreciación por mi parte, para el TCFA (a la espera, entonces, de la decisión prejudicial OMT) pareciera haber operado como una especie de (suplementaria) «piedra de toque» al efecto de decantar lo que de novedoso encierra su decisión (c).

a) El recurso de queja por inconstitucionalidad tiene por objeto la decisión jurisdiccional de un Tribunal Superior de Justicia que había accedido a la solicitud librada por autoridades italianas de «extradición», mediante efectiva ejecución de una orden europea de detención y entrega, del recurrente, un extranjero (norteamericano, de nacionalidad estadounidense) que en 1992 había sido condenado, en ausencia, a la pena de 30 años de privación de libertad, por actividades delictivas por asociación criminal y posesión y tráfico de cocaína.

El condenado en ausencia acudiría ante el TCFA, en recurso de queja por inconstitucionalidad, imputando a esa decisión jurisdiccional una falta de amparo constitutiva de una vulneración de su dignidad personal, ex artículo 1.1. LF.

El condenado en ausencia, detenido en Alemania, ya en 2014, había alegado reiteradamente en el curso del proceso tendente a su entrega a las

7 A propósito, por otros, cf. C. Mapelli Marchena, El modelo penal de la Unión Europea, Thomson Reuters/Aranzadi, 2014; sigue siendo, de interés, A. SÁNCHEz LEGIDo, La euro-orden, el principio de doble incriminación y la garantía de los derechos fundamentales, www.reei.org (revista electrónica de estudios internacionales, 14, 2007). 
autoridades italianas, deficiencias en el sistema de garantías procesales para su efectiva defensa, frente a las imputaciones que habrían llevado a su condena en ausencia.

En atención a ese alegato, el Tribunal de Dusseldorf acordaría, con fecha 14 de agosto de aquel año, solicitar de las autoridades italianas información complementaria acerca del grado de conocimiento que pudiera haber llegado a tener el recurrente del curso del proceso y a propósito de su defensa en el mismo. Interesándose, así, también por la viabilidad, tras su pendiente entrega, de una nueva vista en la que, estando presente, pudiese el recurrente llegar a cuestionar los cargos que se le imputan.

A la respuesta de la Fiscalía de Florencia, mediante una interpretación posibilista de la jurisprudencia de casación relativa a la normativa procesal de aplicación a casos semejantes (expuesta en detalle en su escrito de 7 de octubre de aquel año), tachada por su defensa letrada de inconsistente e infundada, opondría el recurrente una resolución de la Corte de Casación italiana, de 17 de julio de 2014, de cuya interpretación parecía resultar la aplicación retroactiva, a propósito de casos como el suyo, de una normativa procesal obstativa de la realización de un nuevo proceso en su presencia.

Zanjando el debate, mediante Resolución, de 7 de noviembre siguiente, el Tribunal de Dusseldorf acordaría conceder la rogada «extradición», considerando que de lo dicho por la Fiscalía cabía colegir que la revisión de sentencias semejantes, dictadas en ausencia, no podía considerarse excluida. Y, constatado esto, añadiría que tampoco mediante invocación de la cláusula de orden público nacional podría alcanzarse una conclusión distinta, para exigir a Italia que asegurase la realización de nuevo juicio. Pues, en el contexto ius europeo en el que se pone en práctica la euro orden, se habría de estimar suficiente esa remanente posibilidad de audiencia pública y efectiva defensa. En consecuencia, concluiría diciendo ese Tribunal, resultaría ociosa la pretensión de recabar información adicional o dictámenes complementarios a propósito del estado de la cuestión en Italia.

Y ese el criterio mantenido, en su respuesta a la oposición del recurrente, mediante Resolución dictada, apenas tres semanas más tarde, en la que, mediante remisión al sentido y alcance de la correspondiente garantía convencional europea, ex artículo 6.3 CEDH, se insiste en que una cosa es la pretensión (infundada) de repetición del juicio seguido en su ausencia, y otra cosa distinta (y fundada) es la exigencia de su posible reconsideración en vía de recurso.

En ese sentido, insiste el Tribunal de Dusseldorf, en que en supuestos relativos a la aplicación de la euro orden, no cabría pretender que el estándar nacional (alemán) de exigencia de garantías procesales, según su concreta articulación legislativa en aplicación de las correspondientes 
disposiciones constitucionales, se hubiese de proyectar al marco de otros ordenamientos, tales como el italiano, como si de un estándar de inexcusable aplicación se tratase.

Por lo demás, en vía cautelar, ya en amparo, se sucederían hasta tres resoluciones de suspensión de la decisión recurrida en queja por inconstitucionalidad, al efecto de salvaguardar la efectividad de la decisión por adoptar en amparo, conforme a lo dispuesto en el artículo 32.6, 2 de la ley procesal del TCFA ${ }^{8}$.

El recurrente aduce en su queja por inconstitucionalidad que la decisión jurisdiccional de acceder a la solicitud de entrega a las autoridades italianas, se habría acordado sin que se le garantice una revisión de las imputaciones conducentes a su condena en el proceso librado sin su conocimiento, mediante nuevo juicio?.

Por lo que a la posición oficial se refiere, la Fiscalía comparte la decisión jurisdiccional que acuerda la entrega del recurrente, sobre la base de la presunción de que Italia, como Estado miembro de la UE, queda obligado en la aplicación del derecho nacional por las especificaciones de la Decisión marco, estando, por lo demás, sujeto a los estándares convencionales, puesto que nada hacía pensar que tras la entrega, en Italia, no se fuese a respetar ese mínimo estándar constitucional que comporta la doble exigencia de garantía de audiencia pública y defensa efectiva ${ }^{10}$.

Pues bien, en este caso concreto, el TCFA procede a acordar la devolución del asunto al Tribunal Superior de Justicia, a fin de que se aplique el estándar constitucional sentado que, según la interpretación del TCFA en amparo, se considera de incondicional aplicación, sin que ello comporte en el caso la necesaria inaplicación de unas disposiciones del DUE que, según su interpretación (que por parecerle «clara» no se pone prejudicialmente en cuestión ante el TJUE), no excluyen su sujeción a un estándar semejante.

$Y$, mediante un puntilloso cotejo analítico del estado normativo, jurisdiccional y aun doctrinal (¿en lengua alemana, sin cita alguna de fuente en lengua italiana?) de la cuestión, la Sala Segunda del TCFA considera pintiparada esta ocasión para avanzar en su reafirmación, frente a la jurisdicción irradiante del TJUE, del específico espacio jurisdiccional que, como instancia suprema de interpretación de la LE, le corresponde.

Y en consecuencia, como expresión puntual de insatisfacción ante lo que se considera como una especie de desatenta deriva federalizante por parte del TJUE (así, por ejemplo, cuando se insiste en la exigencia de

8 Cf. A. II (marginal n. $\left.{ }^{\circ} 24\right)$.

9 Cf. A. III (marginales n. ${ }^{\text {os }} 25-7$ ).

10 Cf., en detalle, A. IV (marginales n. ${ }^{\text {os }} 28-33$ ). 
salvaguarda de la efectividad del DUE aun en supuestos de remanencia de un cierto margen de apreciación o discrecionalidad estatal), y acaso como clara advertencia al TJUE que, entonces, aun estaba por decidir la cuestión prejudicial OMT ${ }^{11}$, decide comenzar a mostrar la potencialidad de un control de «identidad constitucional» que, como cláusula comprensiva y de cierre, hasta ese momento, solo se había invocado a título meramente hipotético ${ }^{12}$.

Pues bien, a ese tipo de razonamiento prudencial del Tribunal Superior de Dusseldorf, ha opuesto la Sala Segunda del TCFA, una exigencia de rigor identitario que, si bien se asienta en un bagaje conceptual propio, tiene ante sí ese fallido ensayo dialógico, que realmente ha sido el caso (español) Melloni.

b) Se recordará, a propósito, que el TC español se decidiría a dar el paso de plantear una cuestión prejudicial ante el TJUE, mediante ATC 86/2011, en la idea de lograr un doble objetivo. Por una parte, superar una exigencia de rigor, por estimarse ello excesivo entre Estados sujetos a estándares constitucionales semejantes, cuando no comunes, y, por otra parte, contribuir, mediante formalización, por primera vez, del cauce institucionalizado de diálogo prejudicial, a la clarificación del régimen de concurrencia de los estándares comunitarios y constitucionales, mediante interpretación de las correspondientes disposiciones de la Carta de Derechos Fundamentales de la UE (CDFUE).

La doctrina a superar, sentada a propósito de la pretensión de amparo de extraditables condenados en ausencia, había sido formulada por el TC mediante su sentencia Paviglianiti (STC 91/2000), en la que, no sin

11 A propósito del controvertido Auto TCFA, de 14 de enero de 2014, cf., por otros, mi comentario (Prejudicializando... comentario de la primera cuestión prejudicial del Tribunal Constitucional federal alemán), publicado en TRC 33, 2014, pp. 315-325.

La crítica, que arranca ya del mismo seno del colegio decisorio, como bien acreditan los votos particulares discrepantes formulados por los magistrados Gerhard y Lübbe-Wolf, tendría su continuidad ius europea en las Conclusiones del AG Cruz Villalón, como en los alegatos de algunos de los Estados intervinientes, antes de llegarse a la medida Sentencia TJUE, de 16 de junio de 2015 (cf., por otros, A. SÁrnZ de VicuÑA BARroso, La política monetaria del BCE ante el Tribunal Constitucional federal alemán, en RDCE 55, 2016, pp. 1067-99).

12 Cf., no obstante, la controvertida declaración de inconstitucionalidad de la ley alemana de incorporación de la regulación europea de la euro orden, por una exigua mayoría de los miembros de la Sala Segunda con base en una argumentación que por contraste con los VV PP que la acompañan, especialmente, los de Lübbe-Wolf y Gerhardt, tiende a palidecer (Sentencia del TCFA de 18 de julio de 2005, as. 2 BvR 2236/04, en BVerfGE 113, 273 y ss.).

Una manifestación menos tosca de acomodo de la «identidad constitucional» a las exigencias estructurales derivadas del proceso de integración puede considerarse, sin duda, el ensayo de extensiva interpretación, de conformidad con el DUE, del restricto reconocimiento de la titularidad de derechos fundamentales a las personas jurídicas de nacionalidad alemana, ex artículo 19.3 LF (Sentencia de la Sala Primera, de 19 de julio de 2011, as. 1 BvR 1916/09, en BVerfGE 129, 78, 100). 
controversia manifiesta en sendos votos particulares ${ }^{13}$, el colegio en Pleno amparaba al recurrente, nacional italiano condenado en ausencia, en atención al desconocimiento de un denominado contenido «absoluto», inherente a la dignidad de la persona, causante de una indirecta vulneración del derecho constitucional de defensa, ex artículo 24. 2 CE, imputable, de modo indirecto, a la resolución jurisdiccional cuestionada en amparo, en la medida en que no se atajase la situación de incumplimiento por parte de las autoridades de otro Estado (en aquel caso se trataba de Italia, un Estados partícipe del CEDH y, como España, miembro asimismo de la UE), al no considerarse garantizada la impugnación de la condena impuesta en ausencia del acusado a pena de prisión por delitos muy graves, relacionados con prácticas mafiosas.

El mantenimiento de ese inflexible estándar constitucional, consistente en la indeclinable exigencia de una posibilidad real de revisión de la condena a pena grave dictada en ausencia del recurrente en amparo, no constando su expresa renuncia a comparecer, como conditio sine qua non para conceder extradiciones, sería objeto de controversia creciente, en relación con su proyección a supuestos de aplicación de la orden europea de detención y entrega ${ }^{14}$. Y tanto más, a medida que, en su regulación europea, las exigencias de rendimiento funcional insitas en el principio de mutuo reconocimiento comenzaran a conectarse ya con derechos y garantías procesales en el marco de ese simplificado procedimiento de extradición, al interno del espacio de libertad, seguridad y justicia ${ }^{15}$.

Llegados a ese punto, no tardaría ya mucho el TC en hacer extensivo el debate al ámbito ius comunitario, mediante controvertido planteamiento de una primera (y, de momento, única) cuestión prejudicial (ATC 86/2011), al efecto de clarificar en lo posible un complejo sistema de conjunción de planos y estándares de tutela de derechos y garantías fundamentales a fin de sentar una interpretación satisfactoria que, sin perjuicio del funcionamiento efectivo de ese específico régimen ius europeo de detención y entrega, satisficiera igualmente las garantías de tutela

13 Cf. VV. PP. a la STC 91/2000, de 30 de marzo (ponencia de T. S. Vives Antón), de los magistrados P. Cruz Villalón y M. Jiménez de Parga y Cabrera (al que se adhirieron R. de Mendizábal Allende y V. Conde Martín de Hijas).

14 Cf., en particular, STC 177/2006, de 5 de junio.

15 Cf., así, la común advertencia en sendos VVPP a la STC 199/2009, de 28 de septiembre, por la que se otorgaba el amparo a un condenado en ausencia — en ese caso, en Rumania-, por la inconsecuencia de la pretensión de imponer unos Estados a otros, miembros también de la UE, su particular parámetro de garantía y tutela de los derechos fundamentales.

En esos dos votos particulares se apuntaría, asimismo, a la alternativa de planteamiento bien de una cuestión de inconstitucionalidad de la ley española que hacía suya la regulación de la llamada euro orden, o bien de cuestionamiento, en la correspondiente vía prejudicial, de la propia Decisión marco. 
judicial efectiva y los derechos integrantes del debido proceso (y de su correspondiente derecho a un proceso con todas las garantías, ex artículo 24.2 CE).

Pues bien, al margen de la oportunidad y conveniencia del planteamiento de esas cuestiones en vía prejudicial, lo cierto es que la respuesta del TJUE, mediante Sentencia, de Gran Sala, de 26 de febrero de $2013^{16}$, lejos de contribuir a la pacificación del debate, mediante la traza de perfiles netos en la geometría del triángulo tutelar que resulta del comprometido encuentro del TJUE, de una parte, con el TEDH y, de otra, con los Tribunales Constitucionales (en un doble sentido, formal y material) de los Estados miembros de la UE, incurriría en una lectura reduccionista y secante de la potencialidad que se encierra en los artículos 52 y 53 de la Carta de Derechos Fundamentales de la UE.

La alicorta interpretación del sentido y alcance de esas previsiones del derecho primario, a la luz del derecho derivado, no solo ha generado escaso entusiasmo, sino que ha propiciado una elusiva respuesta por parte del TC que, sin perjuicio de cierta controversia en su seno (según acredita la emisión de tres VVPP que, en uno u otro sentido, discrepan del proceder mayoritario en el Pleno), ha ensayado una salida alternativa a la expresamente indicada por el TJUE en su respuesta a la cuestiones prejudiciales planteadas.

Pues, al tiempo que abandona, mediante la expresa revisión de su doctrina anterior, la inexcusable exigencia previa de salvaguarda de un contenido «absoluto» del artículo 24.2 CE, se anima a formular una solución de compromiso, a caballo de su exigente doctrina anterior y del paupérrimo estándar de tutela formulado por el TJUE.

En aplicación de la cláusula hermenéutica estructural, expresamente formulada ex artículo 10.2 CE (en una línea que, indirectamente, apunta a la idea, adelantada ya in abstracto en su ejercicio de jurisdicción preventiva en relación con el encaje constitucional del fallido TcUE, en los FF JJ 5 y 6 de la DTC 1/2004, de 13 de diciembre, de que el estándar común a la UE y a sus Estados miembros, no siendo uno superior, deberá ser el común denominador que hubiera podido establecer el TEDH, al interpretar el sentido y alcance de los derechos y garantías convencionales), se procede a integrar el parámetro de aplicación en el marco del recurso constitucional de amparo, mediante integración del artículo 24.2 CE, conforme al canon convencional decantado, a propósito de la equivalente garantía del CEDH, en la jurisprudencia del TEDH.

16 Recaída en el asunto C-399/11; cf., por otros, los comentarios de I. Torres Muro (La condena en ausencia: unas preguntas osadas... y una respuesta contundente), en REDC 97, 2013, pp. 343-70, y de Beatriz GARCÍA SÁNCHEZ (TJUE, Sentencia de 26.02.2013, Melloni), en RDCE 46, 2013, pp. 1137-56. 
El TC se muestra relativamente flexible y rigurosamente pragmático, a un mismo tiempo, si cabe decirlo así.

Relativamente flexible, en su decepción, porque, si bien no se considera vinculado por una interpretación expresamente solicitada al TJUE en vía prejudicial que, conforme al sistema de controles operativo en el marco de los Tratados de la UE, resultaría vinculante, tampoco la enfrenta de plano (lo que, en la lógica del sistema de prejudicialidad ius comunitaria, habría exigido el abierto replanteamiento de cuestiones ya planteadas ante el TJUE).

Y en su inconsecuencia elusiva, acomete el TC, asimismo, un riguroso ejercicio de pragmatismo, mostrando su manifiesta disposición a seguir dialogando con el TJUE, bien que de un modo ya indirecto, mediante formulación de una salida de compromiso, a propósito de las solicitudes de entrega en aplicación de la llamada euro orden, en supuestos de condena a pena grave dictada en ausencia, a mitad de camino entre la raquítica propuesta interpretativa del TJUE (sujeta a velada crítica, al negar su valor de estándar sustitutivo y considerarlo solo como un elemento indicativo más al efecto de integrar el operativo parámetro constitucional) y un exigente estándar constitucional previo que expresamente abandona (por más que, en atención a la decepcionante respuesta del TJUE, valiéndose acaso de la invocación de esa cláusula de «identidad constitucional» que, a modo de hipotético alternativo anclaje constitucional, viniera a considerar en sus Conclusiones al asunto Melloni, el AG Yves Bot), para enfilar ese convencional camino de en medio, que consiste en la acogida, como referencia integradora de su inexcusable estándar ius fundamental de tutela, de la cumulativa conjunción de las garantías de efectiva notificación y defensa letrada.

Así las cosas, en la STC 26/2014, de 16 de febrero, al considerarse acreditada esa cumulativa exigencia establecida en la jurisprudencia del TEDH, relativa al artículo $6 \mathrm{CEDH}$, se decide denegar el amparo al recurrente. Distinto habría sido el fallo de no haberse podido acreditar la concurrencia de esa exigencia de cumulativa garantía procesal en un supuesto semejante de condena en ausencia.

En definitiva, si bien el TC no lo dice expresamente, de la STC 26/2014 resulta un manifiesto desconocimiento, en el caso, de la exigencia de efectividad y primacía de una disposición del DUE, interpretada en respuesta a su cuestión prejudicial. Al resolver así la cuestión planteada en amparo, de soslayo, el TC desconoce la exigencia funcional de primacía de aplicación del DUE.

$Y$, en consecuencia, no extraña que en este fallido episodio dialógico, en lo que se alcanza a decir y aun en lo que no se llega a formular, haya podido encontrar el TCFA una cierta inspiración en su empeño de reconsiderar el estado de las relaciones entre el DUE y la LF, mediante su propia modalidad dialógica. 
c) El TCFA pareciera tomar esa enfática reafirmación prejudicial de la Decisión Marco en respuesta al TC español, algo así como un punto de no retorno, ante el que, sobre la explícita invocación de la supremacía constitucional en la STC 26/201417, se hubiese considerado llegado el momento de poner las cosas en claro y sin voluntad alguna de acudir nuevamente ante el TJUE, mediante la que podría haber sido su segunda cuestión prejudicial.

Y en una especie de diálogo distante opone al estándar comunitario sentado en la Sentencia Melloni, limitado a la glosa de la disyuntiva previsión de la Decisión marco y ajeno a la exigencia de revisión del caso, el estándar constitucional previamente configurado. Dejando sentenciado que ese estándar constitucional y no otro, incluso en el marco de correspondencia ordinamental que refleja el principio de confianza mutua y a propósito de una regulación que el TJUE ha considerado de la exclusiva competencia de la UE, es el que se ha de observar al adoptar la decisión jurisdiccional respecto a la solicitada entrega del condenado en ausencia ${ }^{18}$.

Pues, mediante su velada crítica a propósito de la desatención del TJUE a la cuestión de los límites ius fundamentales oponibles al automatismo aplicativo de la directiva funcional de reconocimiento mutuo, pareciera terciar en un debate a resultas del cual, no solo su correspondiente (español), habría quedado insatisfecho.

Esta referencia comparativa, muestra es también de un comparatismo constitucional ius europeo que, partiendo de la paráfrasis de una singularización ya recurrente en el espacio doctrinal alemán, desde la caracterización de la UE como Staatenverbund (vocablo con el que el ponente de la sentencia Maastricht del TCFA abriera una veta, luego enriquecida, mediante paráfrasis sucesivas, tales como Verfassungsverbund o Verwaltungs-, Regierungsverbund, etc. como expresamente se dice en el numeral de esta sentencia $\left.{ }^{19}\right)$, pretende dar cuenta de la emergente confluencia en el espacio compartido de la suma institucional y funcional de los poderes expresivos de la actuación de los Estados miembros de la Unión ${ }^{20}$.

Que el actual (presidente del) TCFA se sumase a ese inventivo festín de las paráfrasis expresivas de confluente yuxtaposición institucional también por parte de los Tribunales Constitucionales, patentando el vocablo

17 La referencia a la STC 26/2014 se encuentra en el marginal n. ${ }^{\circ} 78$.

18 Cf. en detalle, marginales $n .^{\text {os }} 76-83$.

19 Por lo demás, P. KIRCHhof, Der Staatenverbund der Europäischen Union, en J. IsENSEE/P. KIRCHHOF (eds.), Handbuch des Staatlichen Rechts BRD, I, 1987, pp. 745-74.

20 En cierto modo, algo de esta concepción latía ya, si yo no lo he entendido mal, en la propuesta de confluente suma de reformas constitucionales en los Estados miembros en paralelo, o como alternativa, a las reformas del Derecho Primario, formulada por F. RUBIO LLORENTE, El constitucionalismo de los Estados integrados de Europa, en REDC 48, 1996, pp. 9-33 (Constitutionalism in the 'integrated' States of Europe, en Harvard JM WP n. ${ }^{\circ}$ 5/98). 
«Verfassungsgerichtsverbund» ${ }^{21}$, acaso permita entender mejor el esfuerzo del TCFA por mencionar expresamente, con razón o sin ella, resoluciones de otros Tribunales Constitucionales, dando a entender la existencia de un común jurisprudencial que, por su particular activismo, se siente llamado a potenciar, cual referente o guía de la liga de los Tribunales Constitucionales.

De ser esto cierto, la terciada consideración acerca del fallido episodio dialógico en el asunto Melloni, algo dice del nuevo contexto ius europeo, en el que el TCFA pretende comenzar a desenvolverse, de un modo autónomo.

En la medida en que, si expresamente se critica la desatención del TJUE a su función integradora, con ocasión del ejercicio de la jurisdicción prejudicial, de estándares de equivalencia por elevación (esto es, equivalencia, en sentido estricto, o sin perjuicio de la remanencia de un espacio estatal para adicionales estándares constitucionales, o equivalencia plus, o por elevación, de modo que resultase ya innecesaria la adición de estándar complementario alguno al interno del orden constitucional del Estado), implícitamente, se apunta, por lo que al propio TCFA respecta, a la asunción de una responsabilidad indeclinable que, mediante un ejercicio cooperativo, le llevaría ya no a plantear dudas a quien ha tenido la ocasión de responderlas a preguntas de otro y no lo ha hecho, limitándose a repetir tópicos, sino a proponer interpretaciones satisfactorias, por compatibles con los contenidos incondicionales de los estándares constitucionales, en el desempeño de una complementaria jurisdicción de integración constitucional de los estándares comunes (comunitarios).

$\mathrm{Y}$, por lo que a los otros Tribunales Constitucionales se refiere (en el caso Melloni de referencia, se trataría del TC español), siendo consciente de que su propuesta interpretativa de estándar inexcusable no puede imponerse en otros espacios constitucionales, por obvias razones de soberanía y por inconsecuencia lógica, pareciera estar llamando a seguir su senda a esos otros correspondientes. En general, cuando pone sus tópicos presupuestos,

21 Vide, a propósito, A.Vosskuhle, Der europäische Verfassungsgerichtsverbund, en NVwZ 2010, pp. 1 y ss.

Esa invocación a la entrada en escena de la liga de los tribunales constitucionales, encierra seguramente un programa alternativo al de silente acompañamiento del TJUE; como adalides de las esencias de sendas constituciones que son, como garantes conjurados de la estandarización constitucional mínima inexcusable en ese espacio abierto, parecieran estar a punto de ser convocados a eso que P. CRUZ VILLALÓN propone caracterizar de «comunión constitucional» (cf. contribución en este mismo número de TRC, a propósito del término «Verfassungsverbund», en su día apuntado por I. Pernice como paráfrasis constitucionalista del término «Staatenverbund» de raíz kirchbofeana).

En realidad, si se atiende al significado propio del prefijo «ver» (alusivo a la idea de «proceso con resultado final»), quizás esa propuesta de traducción del neologismo en alemán, acaso no resultase del todo inapropiada para dar a entender que al proceso abierto de confluencia de los estados constitucionales en el espacio ius europeo le falta «comunión». 
condicionantes y límites, en relación con las reservas ya formuladas o apuntadas en la jurisprudencia ius europea de otros Tribunales Constitucionales. $\mathrm{Y}$, de modo particular, por lo que al TC español se refiere, cuando se tercia en la discrepancia respecto de la doctrina Melloni del TJUE, poniéndo se (sin decirlo expresamente, pero de modo patente) al lado del TC español, al que acaso, por su reacción elusiva ante la interpretación prejudicial solicitada del TJUE, se considere un posible aliado en esta tarea de conquista constitucional del espacio ius comunitario (por más que el TC español procediese, en su evasiva respuesta a la doctrina Melloni del TJUE, al abandono de su exigencia de incondicionalidad de un estándar constitucional previo, que alguna similitud guardaba con la caracterizada incondicionalidad de los contenidos relativos a la cláusula de identidad constitucional que ahora se ha venido a poner de manifiesto en la referida sentencia del TCFA).

Pero, sobre esa constatación de la insuficiencia de la jurisprudencia del TJUE a propósito de los límites ius fundamentales oponibles en la práctica a las exigencias funcionales derivadas del reconocimiento mutuo de resoluciones jurisdiccionales que caracteriza el espacio europeo de libertad, seguridad y justicia, el TCFA, a diferencia del TC español, sustenta y basa su discrepancia con la jurisprudencia (Melloni) del TJUE, en la invocación de contenidos incondicionales integrantes de la cláusula de «identidad constitucional».

Una cláusula acerca de cuyos contenidos y efectos el TCFA sería responsable, si no en exclusiva, sí en último término.

\section{III. ...Y CONSTITUCIONAL NACIONAL}

a) En consecuencia, a diferencia de ocasiones previas en los que se ha ido gestando el corpus de su jurisprudencia ius europea, en el presente caso, el TCFA no se limita a una mera declaración de admisibilidad del recurso. $Y$ esto significa aquí, en sustancia, dos cosas.

Lo primero, como bien puede entenderse, es que no es posible activar un «control de identidad» sin una cierta superación de su previo acervo jurisprudencial. Pues el «control de identidad», en supervisión de las actuaciones estatales, por acción u omisión, alcanzaría a proyectar su larga sombra sobre el derecho derivado de la UE. Ello supone, por más que no se haga explícita, la superación de una tradicional línea de su jurisprudencia ius europea, en la que se había venido sosteniendo la inadmisibilidad tanto de cuestiones como de quejas por inconstitucionalidad en las que se plantease o adujese una posible vulneración de derechos fundamentales mediante derecho derivado de la UE, salvo por falencia sistémica o deficiencia estructural. 
Sostiene aquí el TCFA que, sin perjuicio de esa línea de jurisprudencia previa (Solange-II y Plátanos) si, tal y como - en su opinión- ocurría en el caso, se le plantea un supuesto de grave vulneración de la garantía de la dignidad de la persona, entonces habría de proceder a su examen en el marco de su anunciado «control de identidad» $»^{22}$.

$\mathrm{Y}$, lo segundo, es que, como quiera que el movimiento se demuestra andando, entendiendo que se le habría planteado una queja bien fundada, se pasa ya de la mera invocación a la efectiva aplicación del «control de identidad», sancionando la inconstitucionalidad de una resolución jurisdiccional que, mediante su decisión favorable a la entrega del condenado, habría incurrido en la vulneración de un derecho (fundamental) del recurrente, ex artículo 1.1, en relación con los artículos 23.1.3 y 79.3, todos de la $\mathrm{LF}^{23}$.

Y, como bien se comprende al hilo de su detalle argumental ${ }^{24}$, ese fallo se pronuncia, no de manera elusiva, o — diríase - al modo Melloni del TC español, sino de manera frontal, mediante una cerrada oferta interpretativa de integración del estándar del DUE de conformidad con los congruentes estándares convencionales europeos (glosados en detalle, no obstante la imprevisión en la LF de una cláusula hermenéutica estructural como la que se contiene en el ya referido artículo 10.2 CE) consonantes, en esta ocasión, con la incondicionada garantía constitucional. Y, en todo caso, conforme al inexcusable estándar constitucional que, como parte integrante de la «identidad constitucional», al TCFA le compete salvaguardar, mediante un desempeño de su específica función jurisdiccional de control que esté en consonancia con su responsabilidad última como garante de la $\mathrm{LF}^{25}$.

b) El TCFA, antes de adentrarse en el detalle de su argumentación, marca una traza actualizada del estado hermenéutico del fundamento constitucional de la integración, como de ordinario, sumando matices, mediante una técnica bien contrastada de «discontinua continuidad».

22 A propósito del detalle de esta novedad, en el apartado B que la formula (marginal n. ${ }^{\circ} 34$ ) se remite, para su pormenorizado desglose, a los contenidos expuestos en los epígrafes 2-5 del apartado C. I.

23 Vide esa declaración en la cabecera del apartado $\mathrm{C}$ (marginal n. ${ }^{\circ} 35$ ).

24 Vide en C. II. (marginales n. ${ }^{\text {s }} 51-124$ ).

25 A propósito de la configuración y relativa (in)concreción jurisprudencial (no solo) de su responsabilidad respecto de la salvaguarda de esa cláusula estructural de «identidad constitucional», vide su jurisprudencia Lisboa (BVerfGE 123, 267, 344, 353-4) y su secuela Honeywell (BVerfGE 126, 286, 302-3); y, asimismo, la secuencia que va del Auto OMT (BVerfGE 134, 366, 384-5) a su reciente Sentencia de 21 de junio de 2016. Cf., de una parte, las contribuciones de A. López Castillo y A.J. Menéndez Menéndez, en La Sentencia Lisboa del TCFA, CEPC, Madrid, 2011, pp. 13-53, 55-205, y, de otra parte, A. López Castillo, Prejudicializando... comentario de urgencia, en TRC 33, 2014, y Antonio SÁinz De VicuÑa BARROSO, La política monetaria del BCE ante el Tribunal Constitucional federal alemán, en RDCE 55, 2016, pp. 1067-99. 
Se recuerda, así, que la expectativa de primacía del DUE, sin la que no sería viable esa comunidad de derecho, en Alemania tiene su anclaje en el fundamento constitucional de la integración que, en la medida en que dispone su participación en la creación y desarrollo de la Unión, contiene «una promesa de efectividad y cumplimiento del derecho de la Unión». $\mathrm{Y}$ se recuerda, asimismo, que con base en esa previsión constitucional, mediante la correspondiente ley de autorización de ratificación, se actualiza la «concesión» de una primacía de aplicación del DUE que alcanza también al derecho constitucional opuesto y que, en caso de colisión, conduce regularmente a su inaplicación. Pues, por mediación del «legislador de la integración», las instituciones y organismos de la UE tanto como las propias autoridades nacionales, en la medida en que ejecutan DUE, quedan liberados de una plena sujeción a las garantías y derechos fundamentales de la LF, por contraste con aquellos otros casos en los que, por disponerse de un cierto margen de discrecionalidad, esas actuaciones y disposiciones quedarán expuestas al control de constitucionalidad.

La continuidad viene de la confirmación de la contribución de Alemania al proceso de integración y de la aceptación de la primacía de aplicación del DUE, con base en el fundamento constitucional de la integración.

Lo que hay de discontinuo, apenas se apunta en esa especie de sintético estado de la cuestión en su jurisprudencia mediante el empleo de expresiones aparentemente inocuas (y que en el texto de la sentencia no se enfatizan) tales como "promesa de efectividad y cumplimiento», "concesión» o «legislador de la integración», antes de su desglose al hilo de la primera puesta en práctica de la novedosa modalidad (ya anunciada, en ocasiones anteriores) de control jurisdiccional del alcance posible en el espacio constitucional alemán de la primacía del DUE, mediante oposición de un parámetro constitucional cuya salvaguarda, como parte integrante de la «identidad constitucional», el TCFA garantiza de un modo incondicional, al resolver las cuestiones o quejas por inconstitucionalidad, mediante un «control de identidad».

c) El control de identidad habría de permitir al TCFA, con independencia de su eventual intervención al efecto de delimitar el alcance de una determinada atribución a la UE mediante examen del «programa de integración» insito en cada una de las autorizaciones del «legislador de la integración» (o control de «ultra vires»), el establecimiento puntual de los límites constitucionales que, en todo caso (es decir, aun siendo ello resultado de una legítima, subsidiaria y no desproporcionada actuación o disposición normativa de la UE), obstarían la aplicación (es decir, pondrían en cuestión la efectividad y primacía) del DUE, en el concreto caso enjuiciado.

Este planteamiento, que en rigor supone una práctica negación de la efectividad y primacía del DUE, tal y como esas inferencias sistémicas 
se han gestado y perfilado en la jurisprudencia configuradora del TJUE, incide en la funcionalidad de la pragmática cláusula de equivalencia que, como exigencia de compromiso al efecto de cohonestar estándares de tutela no necesariamente idénticos, fungía como contingente expresión de compromiso al efecto de superar exigencias lógicamente irreductibles.

Sabido es que la equivalencia como punto de encuentro ha podido convivir con la remanencia de estándares adicionales de tutela en los diversos ordenamientos. Pero no es eso lo que se persigue con la cláusula de «identidad constitucional», configurada y ahora aplicada, en la jurisprudencia del TCFA, por más que el empleo anterior en su jurisprudencia ius europea de vocablos parecidos (así, por ejemplo, el empleo de términos o locuciones tales como «identidad» o «irrenunciable esencialidad» ya en la controvertida decisión Solange de 1974) pudiera dar a entender otra cosa.

La discontinuidad está presente en la incondicionalidad de una exigencia paramétrica que, tal y como se formula, pareciera destinada a operar al margen de la divisoria competencial convencionalmente establecida, lo cual, así como pone en cuestión el recorrido posible de la persistente modalidad de control de «ultra vires», de hecho comporta la irrestricta irradiación, más allá de los supuestos de equivalencia, de sus específicos estándares constitucionales a cualesquiera actuaciones y disposiciones normativas de aplicación en el espacio nacional.

A la hora de justificar no ya el fundamento constitucional interno de esa larga sombra identitaria de la LF, sino su ocasional proyección sobre el DUE, el TCFA se maneja con desenvoltura, tanto al sostener que esa misma «identidad constitucional» estaría insita en el artículo 4.2 TUE y, en consecuencia, sería también compatible con la cláusula convencional de leal cooperación, ex artículo 4.3 TUE, como cuando, a mayor abundamiento, se pasan a relacionar en detalle, algunos hitos de la jurisprudencia de otros Tribunales (Supremos y) Constitucionales que, con ocasión de la interpretación del significado de sus respectivos fundamentos constitucionales de la integración, habrían manifestado también ciertas cautelas por lo que a la delimitación y alcance de la primacía de aplicación del DUE se refiere, mediante invocación de la identidad constitucional o bien por referencia a los límites a la integración ${ }^{26}$.

Dicho esto, el TCFA se lanza acelerada y decididamente, como mostrando a los demás el camino a seguir, en dos largos pasos.

26 El detalle de su prolijo recuento de la variable previsión normativa de las cláusulas de apertura a la integración y de la jurisprudencia constitucional dictada a propósito de su caracterización y límites en otros Estados miembros puede verse en C. I. 2. b) y c), respectivamente. 
El primer paso, consiste en afirmar que, ex artículo 23.1 y $79.3 \mathrm{LF}$, la garantía de la cláusula de identidad constitucional se impone frente a posibles injerencias derivadas de actuaciones de un poder público supranacional. Lo que, dicho de otro modo, significa que la garantía por su parte de la identidad constitucional, así como al control de las manifestaciones de poder público nacional, también alcanza a los supuestos de aplicación del derecho nacional ius comunitariamente predeterminado y bien que indirectamente — si se atiende al efecto de control — a los de inmediata y directa aplicación del DUE.

El segundo paso, es ya una modalidad de interpretación subsuntiva por la que, mediante un ejercicio de decisionismo hermenéutico, se acuerda la extensión de ese reforzado régimen de salvaguarda a un determinado principio o regla jurídica, como manifestación o vertiente de una garantía ius fundamental que sea parte integrante de esa comprensiva cláusula de identidad constitucional.

Y eso es lo que, por reconducción al artículo 1.1 LF, relativo a la dignidad de la persona, se viene expresamente a anunciar, por lo que al principio de culpabilidad en materia penal se refiere ${ }^{27}$.

El tono de cautela, ante la vía de agua que pudiera abrirse a partir de semejante salto paramétrico, vuelve a su discurso, cuando el TCFA, en lo que formalmente se presenta como una interpretación del artículo 79.3 LF a la luz de la directriz de cordialidad ius europea, se reserva en exclusiva la eventual declaración de vulneración de la identidad constitucional, en vía de control de concreto de constitucionalidad, ex artículo 100.1 $\mathrm{LF}^{28}$, o mediante el planteamiento de una queja por inconstitucionalidad en la que se venga a plantear cómo y en que medida pudo haberse producido, en ese concreto caso, la vulneración de la garantía de la dignidad humana que se aduce ${ }^{29}$.

Y en ello centra su atención discursiva el TCFA, mediante un tratamiento ciertamente pormenorizado de las tachas denunciadas por el recurrente en amparo, a lo largo de un extenso apartado C. $\mathrm{II}^{30}$.

d) Pues bien, en este caso, a diferencia de algún otro bien conocido, el TCFA ampara al recurrente no por considerar que la Decisión marco reguladora

27 Vide marginal n. ${ }^{\circ} 48$.

28 Insistiendo, así (marginal n. $\left.{ }^{\circ} 49\right)$, en un paralelismo con la expresa previsión constitucional, ex artículo 100.2 LF, de una cuestión de prejudicialidad aplicativa en relación con las normas del derecho internacional general, que genera más confusión que claridad (pues si bien es cierto que remite al empeño en la reconducción de lo ius comunitario a lo ius internacional, en la línea intensificada ya en la relevante Sentencia Lisboa, no deja de plantear insatisfacción un paralelismo que solo apenas se compadece con la naturaleza y alcance de la imbricación de todos los órganos jurisdiccionales en el conjuntivo espacio de aplicación del DUE).

29 Vide marginal n. ${ }^{\circ} 50$.

30 Que va del marginal n. ${ }^{\circ} 51$ al marginal n. ${ }^{\circ} 124$. 
de la euro orden o la legislación nacional que la incorporaba al ordenamiento jurídico alemán pudiesen haber desbordado los límites (competenciales o) identitarios de la $\mathrm{LF}^{31}$.

El amparo del recurrente se brinda aquí, mediante una interpretación de conformidad constitucional del DUE y de la ley nacional de aplicación, frente a la resolución jurisdiccional dictada en respuesta a la solicitud de su entrega a Italia.

Y ello porque, lejos de considerar la posibilidad de desconocimiento de los estándares de tutela que la identidad constitucional impone, ante la fundada denuncia del recurrente, de segura vulneración de garantías esenciales del procedimiento (al no poder considerarse asegurada una nueva vista pública y la correspondiente práctica de la prueba en descargo de su responsabilidad penal), el Tribunal de Dusseldorf se habría limitado, siguiendo el criterio sostenido por la Fiscalía, a dar por buena una situación de incertidumbre acerca de la efectiva posibilidad de defensa en juicio del recurrente, al contentarse con las insuficientes explicaciones de la Fiscalía italiana, dado lo incierto de la eventualidad de nueva audiencia y práctica de prueba de descargo de una responsabilidad penal que, según la conclusiva justificación del Tribunal, «en todo caso no se excluye».

Una constatación semejante no alcanzaría a satisfacer —en su opiniónunos estándares constitucionales mínimos que, si se mira a la jurisprudencia del TEDH como criterio orientativo (algo que, a su modo, viene haciendo el TCFA), si bien no imponen un nuevo juicio, tampoco se podrían considerar satisfechos por la simple posibilidad de interposición de un recurso, a falta de garantías de audiencia y debate procesal mediante práctica de prueba al efecto de incidir efectivamente en la convicción que forme el Tribunal al efecto de dictar una nueva resolución jurisdiccional.

Al no haberse esforzado en clarificar una situación del todo incierta, el Tribunal Superior de Justicia habría desconocido la necesaria aplicación del imperioso estándar, infringiendo el principio de culpabilidad y, con ello, una garantía ius fundamental del recurrente, ex artículo 1.1. LF, por no tomar suficientemente en cuenta el significado y alcance de la dignidad humana al interpretar la Decisión marco y la ley nacional de asistencia jurídica internacional en materia penal ${ }^{32}$.

31 Cf., a propósito del otorgamiento de amparo mediante una decisión de aplicación de la normativa nacional de aplicación (discrecional) del DUE que, a la luz del artículo 2.1, en relación con los artículos 16.2 y 19.4, todos de la LF, sería declarada inconstitucional mediante sentencia de 18 de julio de 2015, en BVerGE 113, cit. (no sin discrepancia en el colegio decisorio, como bien acreditan los VVPP de Lübbe-Wolf y Gerhardt; menos interés presenta el VP de Bross).

32 A propósito del detalle de esta identificación del estándar constitucional de aplicación, a la luz de los estándares convencionales sentados por el TEDH, mediante aplicación del artículo 6.1 CEDH, a supuestos semejantes, cf. en C. II. 4., marginales n. ${ }^{\text {os }}$ 109-124, en particular, 122-123. 
A esa conclusión se llega en la sentencia de amparo, mediante afirmación de la inexcusabilidad de las garantías procesales al efecto de determinación de la culpabilidad del recurrente, lo que supone una previa determinación de los hechos imputables y de una responsabilidad penal de cargo a falta de lo cual no podría considerarse destruida la presunción de inocencia.

A propósito se establece que, por su conexidad con la cláusula estructural del Estado de Derecho y la garantía fundamental de la dignidad personal, el principio de responsabilidad penal se ha de considerar, como parte integrante de la «identidad constitucional», una garantía oponible también al ejercicio de poder público supranacional. Y tal sería el caso — se insiste- con ocasión de una solicitud de entrega para cumplimiento de condena penal impuesta en ausencia del perseguido.

El TCFA enfatiza la grave trascendencia de la condena en ausencia al recordar que la pena no solo es un reproche jurídico sino también la expresión de una censura moral. A los Tribunales que conocen de solicitudes de extradición les alcanza por ello una «responsabilidad de protección».

En consecuencia, en tales casos son responsables de asegurar el estándar constitucional mínimo. De modo que a falta de información sobre apertura y conclusión del proceso y de la posibilidad, una vez informado, de audiencia y efectiva defensa, no podrían los órganos jurisdiccionales alemanes conceder la extradición. De ahí su obligación de aclaración, de contenido y alcance variable según los casos, a la luz de los estándares ius internacionales de referencia.

Una responsabilidad semejante operaría también, sin perjuicio de la confianza mutua de base, en el específico marco de entrega entre Estados miembros de la UE, si el Estado solicitante no pudiese acreditar que el condenado en ausencia había sido informado y defendido en el proceso o no se dispusiese de una vía de recurso contra la sentencia condenatoria para la revisión de los hechos, incluida la práctica de prueba, que permitiese modificar, en su caso, la decisión adoptada en ausencia ${ }^{33}$.

Llegados a este punto, el TCFA sostiene abiertamente que, sin perjuicio de la primacía de aplicación de la decisión marco, de exclusiva aplicación a los casos de condena en ausencia, conforme a la jurisprudencia del TJUE, el Tribunal no puede eludir un estándar constitucional que, ex artículo 1.1 LF, es parte integrante de la identidad constitucional.

El TCFA recuerda que, sobre la exigencia de interpretación del derecho nacional de conformidad con las Decisiones marco, el TJUE no habría

33 El detalle de la argumentación puede verse en los marginales n. ${ }^{\circ}$ 52-75 (cf., en particular, 72-75, a propósito de la proyección de tal exigencia en relación con la Decisión marco). 
avanzado gran cosa, no obstante habérsele planteado expresamente la cuestión de los límites a la interpretación de conformidad con el DUE, limitándose a insistir en la exigencia de obligada sujeción a sus disposiciones y objetivos, dejando de lado una pretendida aplicación complementaria del derecho nacional, incluso de rango constitucional.

En todo caso, sorprende en alguna medida el TCFA, en relación con este asunto, al concluir diciendo que, en realidad, no sería preciso dejar sin aplicación el DUE, puesto que, ni la Decisión marco, ni la ley nacional que la incorpora al ordenamiento alemán, impiden una interpretación conforme de sus disposiciones al estándar constitucional, ex artículo 1.1. LF, que se impone al órgano jurisdiccional regional cuestionado.

Lo que se propone aquí el TCFA es algo ciertamente novedoso. Pues, de lo que se trata es de ofrecer una alternativa interpretación a la que de modo insistente viene reiterando el TJUE. Una interpretación basada en la afirmación de un estándar constitucional insoslayable, como efectivo parámetro de interpretación tanto del derecho nacional, aun si viniese predeterminado por el DUE, como del propio DUE (pues de facto esa es la consecuencia de la plena sujeción a la cláusula de identidad constitucional de cualesquiera actuaciones, por acción o por omisión, de los poderes públicos, al efecto de sancionar su falta de «responsabilidad por la integración»).

Se propone, así, una especie de salida interpretativa al TJUE, como para ilustrarle, mediante una interpretación congruente con la LF, que no resultaría incompatible con el Derecho Primario de la UE (artículo 6 TUE, en particular), de la Decisión marco que es objeto de controversia interpretativa.

El precio que el TCFA hace pagar al TJUE, indirecta y mediatamente, para no dejar abiertamente sin aplicación, negando su primacía, la Decisión marco, es hacer sus veces, ponerse en su lugar, ocupar su espacio.

Y ello, mediante un ensayo de interpretación autónoma de la Decisión marco que, consciente de la situación creada, se interpreta conforme a las exigencias típicas señaladas por el propio TJUE, tomando en consideración no solo criterios interpretativos diversos (sintácticos, de antecedentes, teleológicos, etc.) sino atendiendo también a la centralidad de la cuestión lingüística en la interpretación del DUE (bien es cierto que, en su línea, el cotejo se limita al trilingüismo recurrente que ha llevado la lengua alemana al centro decisorio de la planta institucional de la UE).

Una interpretación posible del DUE para la que el TCFA busca (a mayor abundamiento) confirmación en la concurrente apreciación de que todos los Estados miembros están sujetos a los DD FF (cf., en particular, artículo 6 TUE) y de que la Carta de DDFF/UE irradia sus contenidos al 
conjunto del derecho derivado; y, en fin, todo ello en el marco interpretativo de referencia que resulta de la jurisprudencia del $\mathrm{TEDH}^{34}$.

En definitiva, viene a concluir el TCFA ${ }^{35}$, como quiera que la Decisión marco se ha de considerar sujeta a un estándar semejante al constitucionalmente integrado por el TCFA, en el presente caso no se habría hecho preciso ir más allá en la indagación, que se deja por ello pendiente para una próxima ocasión, de si, y hasta donde, podría o no considerarse obligada la UE al efecto de sentar el estándar común al interpretar el sentido y alcance de la cláusula convencional de respeto de la identidad constitucional de los Estados miembros, ex artículo 4.2 TUE.

Identidad constitucional, por las buenas o a las malas. En el caso, sostiene el TCFA que a ello se llega por las buenas, mediante un ejercicio de reducción interpretativa que hace decir normativamente al DUE aquello que previamente se establece como contenido propio inexcusable de «identidad constitucional». Pero, en otro caso, de apreciarse una falta de correspondencia o semejanza entre los estándares del triángulo, el estándar constitucional expresivo de esa «identidad» se llegaría a imponer a las malas.

En una perspectiva procesal, se plantea la dificultad de una cooperación dialógica que no se atenga a los estándares constitucionales que, con base reforzada en la cláusula de identidad constitucional, se articulan ya netamente como elementos condicionantes de la operatividad de las reglas existenciales de aplicación en un ámbito de integración.

Por una parte, el TCFA desecha la idea de acudir al TJUE, mediante un ejercicio de interpretación del DUE de conformidad con el estándar constitucional sentado, como conditio sine qua non (acaso, por contraste con lo sucedido en el asunto Melloni, atendida la experiencia ajena, en ese caso, del TC español). Y, por otra parte, se ha de recordar que, una vez que llegue a entrar en vigor la vía de prejudicialidad abierta por el Protocolo n. ${ }^{\circ} 16$ anejo al CEDH, en la medida en que los estándares convencionales no resulten clarificados o dejen un espacio a la duda (claro que, a fortiori, el TCFA, en un marco de discrecionalidad semejante, bien puede proceder a integrar los estándares convencionales, asimismo, de conformidad con el estándar constitucional sentado como expresión de su «identidad constitucional»).

34 A propósito del detalle, en este punto, se remite a los marginales n. ${ }^{\circ}$ 91-104. Por lo demás, el TJUE ha apuntado ya a la necesaria limitación del principio de reconocimiento mutuo al efecto de correcta salvaguarda en estándares convencionales en atención al caso (cf. STJUE de 5 de abril de 2016, ar-ac-C-404/15 \& C-659/15, PPV, Caldaruru y Aranyosi (of., por obras, R. BUSTOS GISBERT en RGDE40, 2016).

35 Cf., a propósito, marginales n. ${ }^{\text {os }} 105-7$. 
Y algunas dudas deja la sentencia que es aquí objeto de comentario a propósito de esa futurible vía de integración ius internacional de la identidad constitucional, como dudoso es, asimismo, el alcance de la propia cláusula constitucional ${ }^{36}$.

\section{CONSIDERACIONES FINALES, A MODO DE CONCLUSIÓN}

Llegando al final, las preguntas se acumulan: ¿Por qué es esta resolución continuista en su discontinuidad? ¿Es solo un hito o también un jalón? En la misma ¿se trata solo de una manifestación expresiva de cierta innovación o variación de su doctrina ius europea o esconde algo más? Y, si vale expresarlo así, ¿Es solo una resolución jurisdiccional de integración del sentido y alcance de la Ley Fundamental (LF), cuyos efectos pudieran limitarse al interno de su espacio de aplicación, o tiene también algo de «decisionismo ilustrado»? Es decir, ¿Es que esta resolución, sobre ser expresiva de una línea de política jurisdiccional, alcanza a formular incluso un «juicio de voluntad»? ¿Es que el TCFA funge como albacea de la desatada voluntad política del constituyente (ex artículo $146 \mathrm{LF}$ ), antes que como el supremo intérprete constituido intra muros de la LF (ex artículo 79.3 LF)?

En todo caso, se trata de un ejercicio jurisdiccional particularmente desenvuelto, desatado (interpretación configuradora de las previsiones de su ley procesal) y creativo (asociación, por analogía, de sus diversos procedimientos, incluidos los atinentes al control relativo al estado de vigencia de normas internacionales) y auto suficiente (sin necesidad de esperar a la intervención del legislador, al que, en la sentencia Lisboa, expresamente se exhortaba a emprender una regulación al efecto).

Y de relativamente contenida (en el sentido de contención, no de contenido) pulsión política (dimensión de política judicial, de creciente manifestación pro activa: control de responsabilidad de órganos políticos animados al efectivo desempeño de sus funciones conforme a los estándares constitucionales, sin perjuicio de señalamiento de condicionamientos y límites al efecto, bien para condicionar ex ante el sentido y alcance de suscribir convenciones paracomunitarias mediante una cláusula dirigida al Gobierno federal, bien para su inclusión en una expresa

36 A propósito, puede verse el ensayo de diferenciación de interpretaciones posibles del alcance de la referida cláusula de identidad constitucional, M. NetTesheim, Anmerkung zu BVerfG. Beschluss vom 15. Dezember 2015, en JZ 2016, p. 427. Por lo demás, cf. las atinadas consideraciones de Frank Schorkopf, $B V \operatorname{erf} G$ aktiviert Identitätskontrolle: Karlsrube will Kommunikation, nicht Konfrontation, en Legal Tribune Online, 29.01.2016 (<http://www.lto.de/persistent/a_id/18318> (visitado con fecha 18 de marzo de 2016), que recuerda, de modo pertinente, cómo apenas unas semanas antes en relación asimismo con un caso de orden europea procedente de Bélgica y dirigida contra un ciudadano alemán, la decisión adoptada en el seno del TC ha descansado en el artículo 16.2 LF, la cláusula constitucional que explícitamente reconoce la garantía de la no extradición de nacional (vide Auto de la Sección 3. ${ }^{a}$ de la Sala Segunda del TCFA, de 7 de octubre de 2015, Az. 2 BvR1860/15), y no en el artículo 1.1 LF. 
reserva, bien para supervisar su consecuente acomodo al marco constitucional de referencia, ex post (cf. STCFA OMT), bien para su imposición en la negociación pendiente (cf. Auto TCFA CETA), etc.

Por todo esto, bien puede afirmarse que, finalizando 2015, en la Sala Segunda se confirma que el TCFA pretende dar por superada una larga fase de observancia de la divisoria competencial entre TJUE y TCFA. Pues, a la contrastada línea de jurisprudencia relativa a su remanente jurisdicción de salvaguarda de esa divisoria competencial, se suma, enfatizada, la reivindicación de una jurisdicción complementaria, de tutela (en este caso) de un derecho fundamental a la dignidad personal garantizado ex artículo $1 \mathrm{LE}$, al margen de que su posible desconocimiento o menoscabo pudiera haber traído causa directa del DUE.

$\mathrm{Y}$, en consecuencia con ello, que, de la imagen de auto contención que ha caracterizado su doctrina relativa a la tutela de irrenunciables esenciales, superando la secuencia de repliegue táctico, que va de Solange-I a Solange-II (1986) y Plátanos (2000), en la que sin perjuicio de la ocasional inobservancia de contenidos nucleares ius fundamentales, se declaraba en suspenso una jurisdicción de control que solo en supuestos de falencia sistémica y fracaso estructural se vendría a reactivar, se pasa ya a la reivindicación de una complementaria jurisdicción de control de la «identidad constitucional», de la que, mediante su nutricia conexión a la cláusula de dignidad de la persona, ex artículo 1.1. LF, los derechos fundamentales harían parte.

En el desempeño de esta complementaria (y, por definición, puntual o casuística) función jurisdiccional, ese parámetro constitucional, sería de aplicación incondicional a cualesquiera actuaciones de poder público al interno del ordenamiento nacional, ya no solo frente a las actuaciones nacionales no predeterminadas por el DUE, sino también frente a las predeterminadas o, en su caso, frente a las actuaciones que, por acción o por omisión, mediante elusión de su responsabilidad por la integración, no emprendiesen o sí, las autoridades competentes al efecto de obstar la aplicación del DUE.

La consecuencia inmediata de esta reconsideración del objeto y parámetro de control de constitucionalidad, conforme a los precedentes doctrinales sentados en su jurisprudencia de entre siglos (así, en particular, en las condicionadas decisiones interpretativas sobre los Tratados de Maastricht, 1993, y Lisboa, 2009), sería la inaplicación al interno del ordenamiento nacional de las disposiciones o actuaciones lesivas de la «identidad constitucional».

En el marco de su jurisdicción de control de constitucionalidad con base en el parámetro de la «identidad constitucional», el TCFA no se limitaría ya —a diferencia de lo que resulta de la formulación de su control de ultra vires, en materia competencial - a los supuestos en que se constatase la falta de base jurídica alguna o bien se apreciase el desconocimiento de los presupuestos y exigencias derivadas de los principios funcionales de subsidiariedad y proporcionalidad.

En el marco de su jurisdicción de control de la salvaguarda de la «identidad constitucional», el TCFA solo estaría constreñido por la propia LF, lo que, en 
atención a su suprema función interpretativa (salvando la hipótesis de arbitrariedad rampante en abierta contradicción con la exigencia constitucional de corrección funcional y, en todo caso, con la cláusula estructural de no disposición del poder constituyente, en relación con la cual resultaría imposible sostener la existencia de algo más que un decisionismo ilustrado o de apariencia jurisdiccional), mermaría en buena medida la seguridad jurídica y certeza ius comunitaria que la aplicación del DUE al interno de los Estados miembros, por definición, demanda.

Y ello porque, con independencia de la regularidad formal y efectiva aplicación de la concreta disposición del DUE que resulte cuestionada, ya sea directa o indirectamente, según se trate de disposiciones de eficacia inmediata o mediata, el TCFA se reserva la función de determinar el sentido y concretar el alcance de la «identidad constitucional» de cuya salvaguarda se encarga en exclusiva.

Que tal situación no se traduzca en cuestionamiento o menoscabo de la efectividad de las obligaciones derivadas del DUE en el espacio constitucional en el que se constituye y erige en su operativo supremo intérprete, (tal y como ello se formula, de forma ciertamente imprecisa), es algo que el TCFA proteicamente deja en sus manos.

Tanto, mirando de puertas adentro, en la medida en que se reserva el control de las actuaciones de los órganos políticos, mediante invocación de la directiva de responsabilidad por la integración, y en la medida en que, por analogía con lo que es el caso a propósito del estado de vigencia de las normas generales del derecho internacional, ex artículo 100.2 LF, llama a los órganos jurisdiccionales ordinarios a elevarle las cuestiones pertinentes al efecto. Como si se mira, de puertas afuera, o eso parece, al menos, dar a entender el TCFA, cuando se apunta que, en aplicación de su jurisdicción de control de la «identidad constitucional», a diferencia de lo que ha venido sosteniendo a propósito del control de «ultra vires», podría no resultar necesario acudir al TJUE, en vía prejudicial.

Y tal habría sido el caso, en esta ocasión. Pues, sin perjuicio del avance doctrinal, el TCFA se lanza a la tarea de interpretar el DUE de conformidad con la LE, mediante el expediente de enjuiciar la constitucionalidad de la legislación nacional aplicable al caso, como paso previo a la interpretación de la normativa del DUE, de la que esa legislación traía causa, de conformidad con esa interpretación constitucional conforme de su propia ley, valga la redundante formulación. Al proceder de este modo, el TCFA se sirve de su unilateral interpretación del DUE para sostener que la cuestión es clara y que, por ello, no precisa plantear cuestión prejudicial alguna.

Con todo, la conclusión unilateral de claridad de una determinada interpretación del DUE, conforme a la identidad constitucional nacional, si bien sirve a su aplicación en el caso, nada definitivo dice sobre el sentido y alcance de una regulación cuya interpretación, según la divisoria persistente en el espacio en proceso de integración, corresponde en último término al TJUE, en cooperación prejudicial, en su caso, con los «órganos jurisdiccionales» que, a esos efectos, comprenden también a los Tribunales Constitucionales. 
Pero lo cierto es que el TJUE hará bien en entender que lo que el TCFA ha resuelto declarar supone tanto como decir que, como en ese caso el DUE admitía una interpretación que resultaba conforme con la exigencia constitucional inexcusable, como parte integrante de la identidad constitucional, ha sido posible su aplicación en suelo alemán. Lo que, dicho de otro modo, significa que, de no haberse alcanzado esa misma conclusión, el TCFA habría declarado la inaplicación en el caso del DUE.

En otras palabras, al TJUE se le ha dejado saber, sin consulta previa alguna, que la interpretación de conformidad es el compromiso que el TCFA puede considerar, en su caso, para no dejar expuesto a inaplicación el DUE en el ámbito de su jurisdicción. Pues, según se dice, la expectativa de la primacía de aplicación que el legislador de la integración consiente tiene su tope inexpugnable e insuperable en la «identidad constitucional». Siendo ello, en opinión del TCFA, conciliable con la conjunción de ordenamientos, no jerarquizados, en el marco de la «Verbund...». Y, por lo demás, menos comprometido para su prestigio institucional — podría haber estado tentado de decir el TCFA, pero lo cierto es que nada parecido a eso se dice-, vista la experiencia previa de planteamiento de cuestiones por su parte y de la correspondiente respuesta prejudicial del TJUE.

Si en relación con el caso OMT se había acudido al TJUE con una variada oferta, gritada y susurrada al mismo tiempo, preanunciando las posibles consecuencias de una desatención grosera de sus pretensiones interpretativas, en este caso, se prescinde de esa enojosa situación de espera y se asume sin condicionamiento alguno la interpretación del DUE que se ha adoptado, al efecto de permitir la aplicación interna del concernido DUE.

Y entonces al TJUE le queda la opción, indirecta, de asumir una interpretación previamente formulada de modo unilateral por un órgano jurisdiccional cuya interpretación no produce efectos externos al ordenamiento en cuestión. $\mathrm{O}$, en otro caso, la alternativa de sentar una interpretación distinta, asumiendo o no un riesgo de desobediencia, según que siente un estándar más cualificado o no.

En definitiva, que para el TCFA el tiempo del táctico repliegue «en tanto que» ha quedado ya superado por este nuevo enfoque, más estratégico que táctico, que le resitúa como instancia decisiva para la efectiva aplicación del DUE en Alemania.

$$
* * *
$$

TITLE: STOP THERE TO THE CONSTITUTIONAL IDENTITY! A (not so) recent example of continuity discontinuity in the jurisprudence of the GFCC.

ABSTRACT: Through this significant decision, the TCFA proceeds to activate its announced constitutional identity control. In doing so, really does not care the primacy of application of the EUS and establishes on a basis extraneous to the Community requirement its relationship with the ECJ, proceeding to interpret the EUS according to the dignity of the person, as an integral element of the unconditional constitutional clause of Constitutional identity, without being subject to a previous preliminary ruling, which, against all evidence, is limited to consider unnecessary in the case. 
RESUMEN: Mediante esta significativa decisión, el TCFA procede a activar su anunciado control de identidad constitucional. Al hacerlo, cuestiona de facto la primacía de aplicación del DUE y establece sobre bases ajenas a la exigencia iuscomunitaria su relación con el TJUE, procediendo a interpretar el DUE conforme a la dignidad de la persona, como elemento integrante de la incondicionada cláusula constitucional de identidad constitucional, sin sujetarse a un previo planteamiento de cuestión prejudicial, que -contra toda evidencia - se limita a considerar innecesaria en el caso.

KEY WORDS: Personal dignity, constitutional identity control, euro order, interpretation of the DUE in accordance with the LF, constitutional limits to the primacy of application of the DUE.

Palabras Clave: Dignidad de la persona, control de identidad constitucional, euro orden, interpretación del DUE de conformidad con la LF, límites constitucionales a la primacia de aplicación del DUE.

FECHA DE RECEPCIÓN: 30.12.2016

FECHA DE ACEPTACIÓN: 01.02.2017 